\title{
Case-study of an Educational Engineering Project: a Series Hybrid Electric Kart
}

\author{
P. Tant, K. Engelen, P. Jacqmaer, K. Clement, J. Verveckken, S. De Breucker, J. Driesen, G. Deconinck \\ K.U.Leuven, ESAT - ELECTA, Kasteelpark Arenberg 10, B-3001 Heverlee (Belgium), \\ tel. +32(0)16321020, fax +32(0)16321985, peter.tant@esat.kuleuven.be
}

\begin{abstract}
The students enrolled in the Energy Master's program at the K.U.Leuven are expected to study and develop a series hybrid electric go-kart during their first Master year. Their main goal is to develop control algorithms in Matlab/Simulink for the different power electronic modules present on the kart. This allows students to work in small sub-groups, each group focusing on their own specific problem. At the end of the project, the solutions found by the separate groups are combined, and integrated on the kart's single board computer which governs the power electronic modules. If they succeed, students can drive the kart around, while using the wireless link to gather and study real-time current, voltage and speed measurements of the kart in motion.
\end{abstract}

Keywords: series hybrid electric vehicle, electric kart, educational project

\section{INTRODUCTION}

The engineering curriculum at the K.U.Leuven consists of three Bachelor and two Master years. In the first year of the Master in Energy program, which is organised by both the electrical and mechanical departments of the K.U.Leuven, the students are required to work on the project described in this paper. The aim of this project, which is worth 5 ECTS credits, is to encourage independent thinking, to improve problem-solving, information gathering and teamwork skills and to stimulate creativity. The project also serves as a preparation for next year's Master thesis. The students are required to integrate the theoretical knowledge they have gathered during the previous and on-going years. It is often the first time the students have to solve an open-ended problem, where more than one solution is feasible. Furthermore, different courses, dealing with energy management, power electronics and drive systems, are combined in this project.

The project focuses on the development of a hybrid kart. This gives students the opportunity to acquire hands-on experience with electric and hybrid vehicles, energy management and battery technology.

In order to cope with the growing number of students it was necessary to re-evaluate the existing student project described in [1]. Before the Master in Energy program became interdepartmental, the kart was a didactical project limited to no more than 15 students. They all had the same task, to design a control scheme for the induction motor on a battery powered, purely electric kart.

When the interdepartmental master started, the number of students participating in the project rose to between 30 and 40. It was no longer feasible to let all students work on the same motor control scheme. Instead, a hybrid electric kart was conceived, which serves as an elaborate hardware platform with a variety of different onboard systems and power electronic modules. This creates the opportunity to divide the project into different sub-problems, which can be solved by smaller groups. This educational project is therefore well suited for larger groups of students.

In the next section, the hardware and the main components of the kart are described. In section III, more general information is provided about the educational aspects of this project. Section IV then deals with each sub-problem individually, and gives details about the specific tasks associated with these problems. Finally, conclusions are given in section V.

\section{OVERVIEW OF THE HARDWARE}

The main components of the hybrid kart are shown in Fig. 1. The kart is powered by a three-phase, $4 \mathrm{~kW}$ induction motor, which is controlled by a field oriented control algorithm. A step-down belt transmission connects the motor with the rear axle.

Electrical energy is supplied from two different sources: a $96 \mathrm{~V}$ battery pack on one hand, and a portable petrol generator on the other hand. The battery pack consists of 8 series connected 12 V/30 Ah leadacid absorbed glass-mat (AGM) batteries. The batteries are located at both sides of the kart, in an aluminium casing which also contains an ultra-rapid $100 \mathrm{~A} / 500$ $\mathrm{V}_{\mathrm{AC}}$ fuse and a thermal magnetic circuit breaker with a $100 \mathrm{~A} / 125 \mathrm{~V}_{\mathrm{DC}}$ rating. A small, commercial $1.6 \mathrm{kVA}$ fuelled generation unit is mounted on the back of the kart, and delivers a $230 \mathrm{~V}_{\mathrm{AC}}$ single-phase voltage.

In a series hybrid electric vehicle, the drive train and the engine are not mechanically coupled. Instead, the engine drives a generator which, in turn, delivers electrical energy to a common DC link. This is represented in Fig. 2, which shows a schematic overview of the electrical power flow in the kart. The battery packs and the inverter for the asynchronous drive motor are connected to the same DC link. When driving, the drive motor usually extracts energy from the common link, but injects energy during regenerative braking. The excess energy is then stored in the batteries. As Fig. 2 shows, the power flow from the batteries and towards the drive motor is bidirectional. The generation unit is unable to absorb 


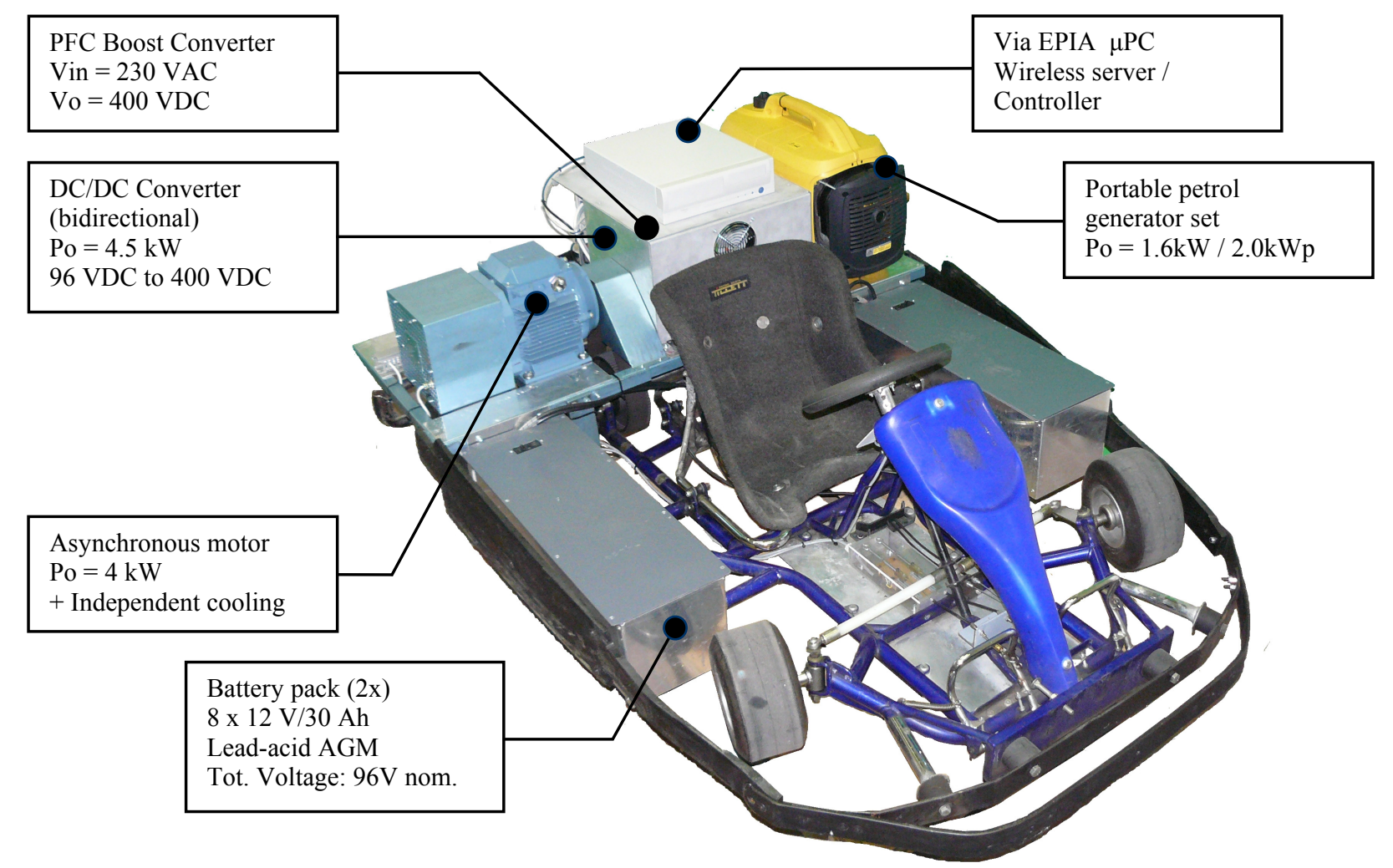

Fig. 1: Photograph of the series hybrid electric kart, with indication of the main components.

energy, its power flow is therefore unidirectional. The energy flow between the battery packs, the generator, and the motor is governed by three main powerelectronic modules (also indicated in Fig. 2):

- The inverter transforms the $400 \mathrm{~V}$ DC link voltage into a three-phase voltage for the induction motor, using a field oriented control (FOC) algorithm.

- A $4.5 \mathrm{~kW}$ bidirectional buck-boost converter (BBC) steps up the nominal 96 VDC battery voltage to the common DC link voltage. In reverse direction of power flow, the converter operates in buck mode and limits the battery charging current to an appropriate level.

- The portable petrol generator delivers a singlephase, sinusoidal 230 VRMS AC voltage. A 1.6 kW Power Factor Correcting (PFC) boost converter converts the generator output voltage into the 400 V DC link voltage, while ensuring that the power extracted from the generator is purely active and that the available output power is used to the full extent.

The energy flow is then regulated by controlling the power that each component (inverter, BBC, PFC) injects in or extracts from the DC link. In the meanwhile, the BBC maintains the DC link voltage at a constant level of $400 \mathrm{~V}$. The output power of the generator set is effectively controlled by adjusting the
PFC output current. In case the generator power is higher than the required drive power (induction motor idling), the buck-boost converter absorbs the excess energy, and recharges the batteries. Likewise, during regenerative braking, the excess energy is recycled to the batteries.

The previously described power electronic modules are integrated on a rapid prototyping platform [4]. This platform allows the students to build their control schemes in the user-friendly Matlab/Simulink environment, compile and download these algorithms, and then immediately try them out on the real hardware. They can also test their control schemes by means of simulations before it is actually used on the power electronic equipment. The algorithm runs on an onboard VIA EPIA computer on the kart (Fig. 2). A number of current, voltage and speed measurements are collected by the platform in real-time, and further processed by the control algorithm. The onboard computer is equipped with a wireless network adapter, which allows sensor data to be gathered and studied on a remote computer, even when the kart is moving. Furthermore, the parameters of the control scheme (e.g. motor speed, model constants, energy flow,...) can be changed while driving, from within the Simulink environment. 


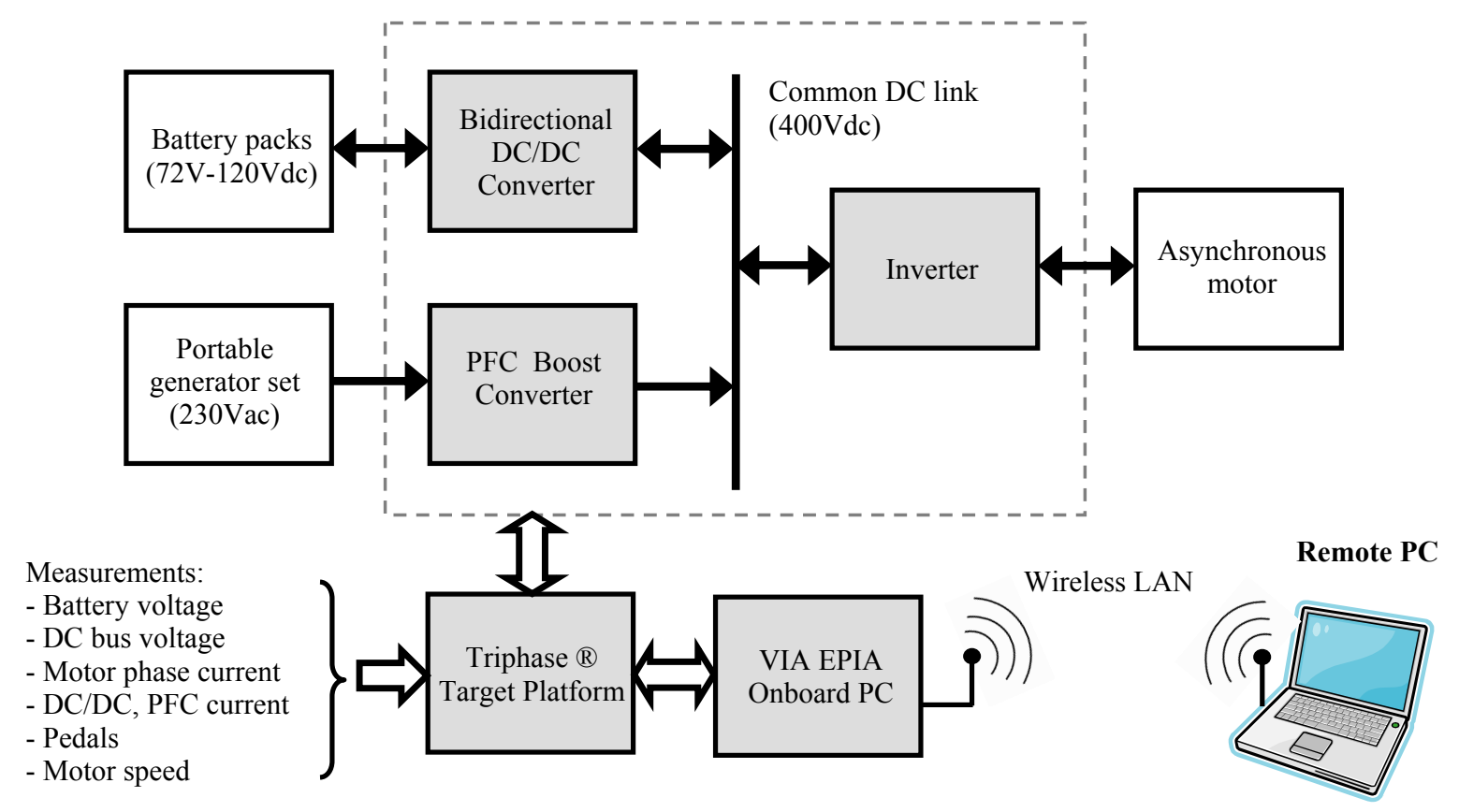

Fig. 2: Schematical overview of the kart hardware and main power electronic components

\section{3}

\section{EDUCATIONAL ASPECTS}

\section{A. Teaching method}

Two different teaching methods have been tested in the last two years. During the first year of the project, teaching assistants (TAs) guided the students intensively and supplied them with all the information necessary to solve the problem. From the second year on, the students are guided less intensively, they have to search most of the essential information by themselves. Questions are only answered when they are posed. Once a week, compulsory sessions of 2.5 hours are organized for the students to work on their project. During these sessions, they have computers with the necessary simulation software (Matlab, Simulink, PLECS) at their disposal [6]. Also, TAs are permanently available during these hours to answer questions. At the beginning of each session, students and TAs have a short, five minute meeting to report on the progress of their work, and to discuss how to proceed in the upcoming session. The students are also encouraged to work in between the compulsory sessions, either at home or at the university. Especially at the end of the semester, when the deadline draws closer, some of the students spend several additional hours on the project, fine-tuning the control models they developed.

\section{B. Organization}

The project is organised during both semesters of the academic year. In the first semester, the students familiarize themselves with the general concepts of hybrid electrical propulsion systems. They design and dimension components of the kart (motor power, belt transmission, battery packs), and try to optimise the energy efficiency of their vehicle by means of simulations. The end result of their work in the first semester is a control scheme that governs the energy flow management in the hybrid kart.

The actual development of the hybrid electric kart takes place in the second semester. At the beginning of the semester, the students are asked to make groups of 6 to 8 persons, which are again divided into 3 subgroups responsible for the buck-boost converter, the PFC converter, and the induction motor control scheme respectively. Initially, each subgroup works individually on its own problem. At the end, the entire group (6-8 persons) attempts to incorporate the various control schemes into one common top-level scheme in which the battery and energy management takes place.

\section{Evaluation}

The students are permanently evaluated during the semester, based on their cooperation within the groups and subgroups and the work they perform during the organised sessions. They are expected to make a short summary after each session, in which they describe the goals they reached that day, and a work plan for the next week.

At the end of the semester, the students deliver a final report and give an oral presentation to practise their writing and oral skills, on which they are also evaluated. The integrated control schemes of each different group are then implemented onto the kart, and evaluated by driving the kart around the parking lot of the department. 


\section{PROJECT CONTENTS AND RESULTS}

In other, similar educational projects, the students often design and build an electrical go-kart themselves, sometimes from the ground up [2-3]. Here, however, a different approach is taken. The kart is pre-built by the TAs, and can be seen as a hardware platform that does not fundamentally change throughout the year. It is the task of the students to study the available hardware solutions, to develop control algorithms in software for the existing hardware and to put the algorithms into practice once they are fine-tuned.

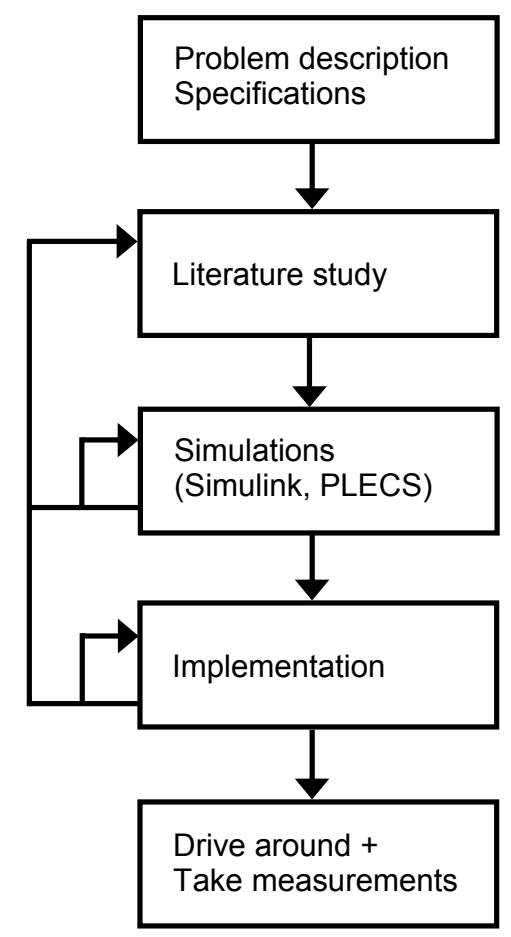

Fig. 3: Project organisation.

Fig. 3 illustrates how the project is organised in time. The students start from a problem description, which depends on the hardware component they have chosen, and a set of specifications. They should realise that the control models of the other sub-groups rely on these specifications and if they are not met, the final integration of the different modules will fail. Then, students perform a literature study (using books, technical papers, lecture notes and the internet) in order to familiarize themselves with the hardware and existing control methods. Afterwards, the Matlab Simulink and PLECS toolboxes are used to design control models. By means of simulations, the students continuously develop and evaluate their designs. If they are confident that their design meets the given specifications, and if they can prove this with simulation results, the model is implemented on the real hardware. Finally, when all sub-groups have completed their control schemes, the models are integrated and tried out on the kart.
The same design process is followed by all sub-groups. The individual contents may vary, however, depending on which hardware component the sub-group is working on. The following paragraphs discuss the specific tasks and teaching methods associated with each component. More technical details about these power electronic modules can be found in [5].

\section{A. Motor Control Scheme}

The hybrid kart is equipped with an asynchronous induction motor. In similar electric kart projects, DC motors are often preferred because they are easy to control, have a high power to weight ratio, and require a relatively simple power electronic converter. From an educational point of view, however, torque control of an induction motor is more demanding and offers more potential with respect to learning activities.

A $4 \mathrm{~kW}$, standard $230 \mathrm{~V} / 400 \mathrm{~V}$ asynchronous motor is mounted on the kart, and driven by an inverter circuit with three half-bridge modules. The hardware platform provides measurements for the phase current in each half-bridge, the DC link voltage, the state of the gas and brake pedals, and motor speed through an incremental encoder. The control model uses these measurements, and calculates the duty cycles for each half-bridge at a certain sample rate (typically $10 \mathrm{kHz}$ ).

The main goal for the students in this sub-group is to develop a field oriented control algorithm for the motor, which allows forward and backward driving, as well as regenerative braking. They start with the design of a simple voltage over frequency (V/F) algorithm, without torque control, to get acquainted with the hardware platform and the software tools. In the beginning, a Simulink asynchronous motor model is used for the simulations. Later on, the software motor model can easily be substituted by the real motor hardware. Using the $\mathrm{V} / \mathrm{F}$ algorithm to drive the motor at first, a step by step design procedure is followed to develop the field oriented control algorithm. To start with, the incremental encoder is read out in order to determine the motor speed. This information is then used to estimate the motor flux and to decompose the measured phase currents into direct-axis and quadrature-axis components. In the subsequent steps, the students close the control loop by actively controlling the direct-axis and quadrature-axis currents, and thus the magnetic flux and torque of the induction motor. The driver controls the torque by pressing the accelerator and brake pedals. The step by step design procedure gives the students the opportunity to debug their own control models, and to learn from their own mistakes as they go along.

\section{B. Buck-Boost Converter}

The buck-boost converter (BBC) enables the bidirectional transfer of energy between the low voltage battery pack and the high voltage DC-link. The 
control system of the BBC maintains the DC-link voltage at its nominal value of $400 \mathrm{~V}_{\mathrm{DC}}$. In reverse direction, the converter operates in buck mode and limits the battery charging current to an appropriate level. The power delivered or absorbed by the BBC is the difference between the generator power and the motor power. The converter is designed to operate with an input voltage ranging from $72 \mathrm{~V}$ to $120 \mathrm{~V}(96 \mathrm{~V}$ nominal) at a rated output power of $4 \mathrm{~kW}$.

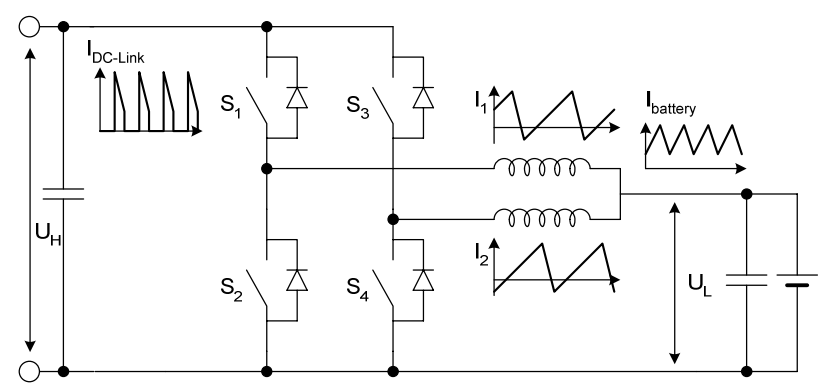

Fig. 5: Interleaved converter topology, and current waveforms at different locations in the circuit.

The converter topology adopted for this project is shown in Fig. 5. Two half-bridges, equipped with IGBT-switches, are operated in parallel with a phase difference of $180^{\circ}$ (interleaved mode). The interleaved operation of the two phase-legs results in a significant reduction of the current ripple at both the high-voltage and low-voltage side.

The students start with the simulation of a simple, single-stage buck-boost converter in PLECS [6], to get acquainted with the behaviour of the circuit and its input to output transfer function. Next, they are asked to design a controller for the PLECS converter, in order to keep the output voltage at a constant level. Since they have complete freedom in their design choices at this point, most sub-groups typically come up with a simple voltage mode controller which has only limited performance with respect to stability and response time. As an alternative, average current mode control is proposed by the TAs. After substantial research in literature, the students then apply this control strategy to their simulations, and prove, by means of simulation results, that it has better performance than the original controller they designed. The next design objective is to connect two buck-boost stages in parallel, as illustrated in Fig. 5, and to adapt the control algorithm accordingly. The current mode control technique, recommended by the TAs earlier, proves to be quite useful for this purpose. An additional design problem emerges now, since the total current has to be equally shared between the two stages. Finally, after discretization of the control model, and a thorough investigation of the start-up behaviour of the converter, the controller is implemented on the real hardware. The students then evaluate the performance of their control algorithm, and quickly discover the unavoidable subtle differences in the behaviour of the simulated and the practical converter circuits.

\section{Power Factor Correction Converter}

The portable generator has a nominal power rating of $1.6 \mathrm{kVA}$ at an output voltage of $230 \mathrm{~V}_{\mathrm{RMS}}$. A Power Factor Correcting (PFC) boost converter is used to step up the rectified output voltage of the generator to the DC link voltage of $400 \mathrm{~V}$. The PFC strategy allows a higher overall energy efficiency because only active power is drawn from the generator set. Furthermore, the sinusoidal shape of the phase current poses less stress on the power electronics in the generator.

First, the students have to dimension the different components of the boost converter circuit, including the heatsink for the power electronic components. Next, the PLECS simulation tool is used to explore the boost converter circuit. An example PLECS circuit, with several measurement modules attached, is shown in Fig. 6. The goal is to design a controller which has to boost up the voltage to a constant $400 \mathrm{~V}$, while making sure that the phase current drawn from the generator is sinusoidal.

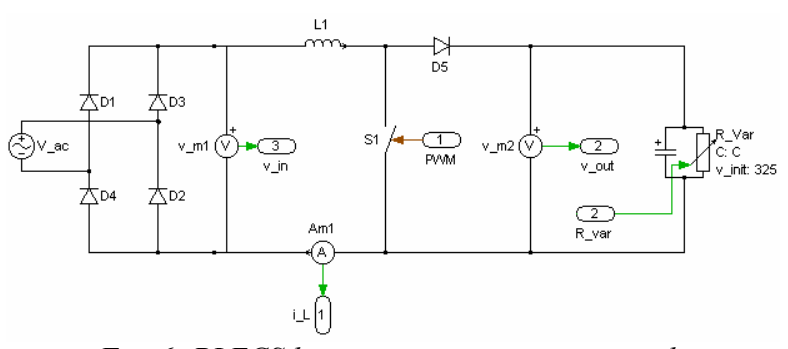

Fig. 6: PLECS boost converter circuit example

Since a large variety of linear and nonlinear control techniques for PFC converters exists, the students have to study the available literature first to make sensible design choices. Typically, the next step is the development of a current control loop, which has a sinusoidal waveform as reference and actively regulates the phase current coming from the generator. A higher-level voltage control loop is then added in order to keep the output voltage at a constant level. Since the initial modelling is done in the continuous time domain, the students also have to discretize the control models and apply sampling quantization at the inputs and outputs of the system. Finally, the control scheme is implemented on the hardware platform, and extensively tested with a separate $230 \mathrm{~V}_{\mathrm{AC}}$ power source.

\section{Top-Level Control Scheme}

The three control algorithms, developed in the previous sections, are assembled into one top-level control scheme that controls the power flows of the battery, portable generator and induction motor. The power that 


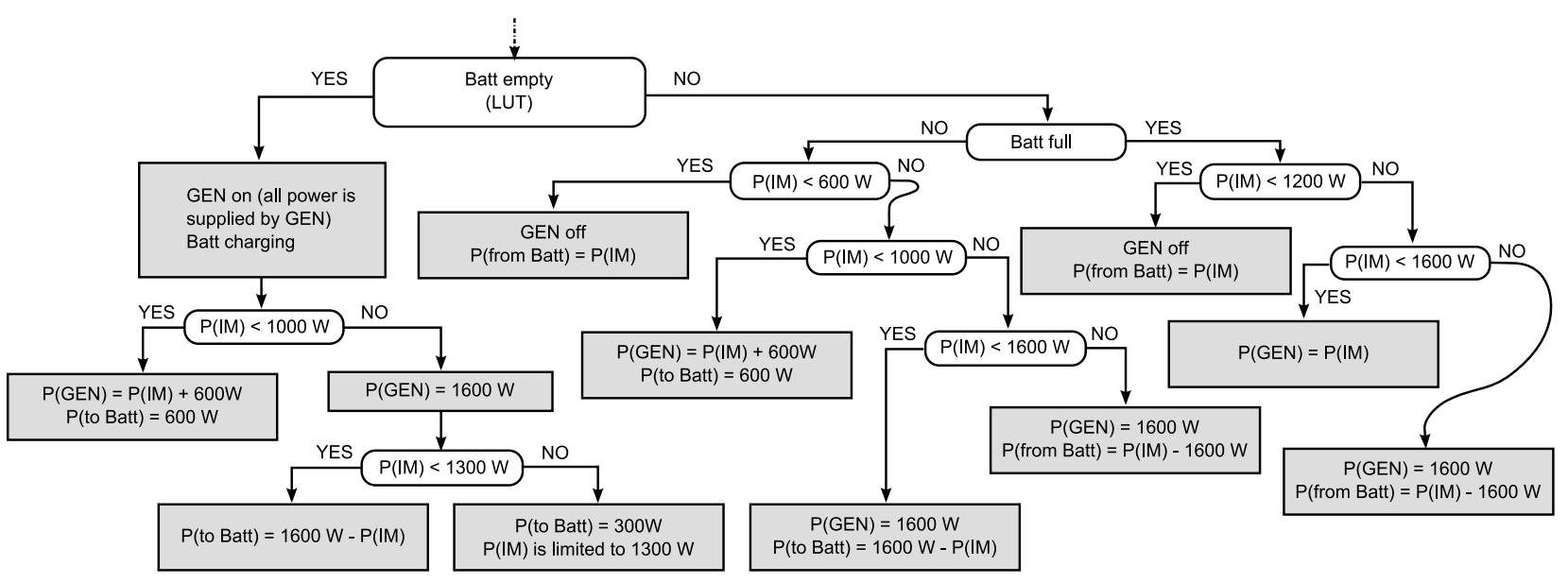

Fig. 7: Top-level control scheme for energy flow management.

the $\mathrm{PFC}$ and $\mathrm{BBC}$ are required to exchange with the DC-link is determined based on the power demanded by the induction motor and the state of charge $(\mathrm{SoC})$ of the batteries. The driver interfaces with the top-level control scheme through the accelerator and brake pedals, and the directional control switch.

A look-up table (LUT), based on data provided by the manufacturer, together with voltage and current measurements, are used to estimate the SoC of the batteries. When the battery voltage drops below a certain current-dependent threshold, the battery is considered empty. The current dependency of the threshold is due to the internal impedance of the battery. A battery in the empty state has to be charged with $100 \mathrm{Wh}$ before it is no longer considered to be empty. Similarly, a battery that was full will no longer be considered to be full when it has been discharged by $100 \mathrm{Wh}$. This hysteresis prevents erratic switching between operating regions.

Due to the poor efficiency of the portable generator at partial loading, the decision was made to operate the portable generator only between $1,2 \mathrm{~kW}$ and $1,6 \mathrm{~kW}$ of output power, except when the battery is completely discharged and the generator becomes the only source of power. In order to prevent the battery from being damaged, the charging power is limited to $600 \mathrm{~W}$. Fig. 7 shows the decision tree used in the top-level control scheme. The idea behind the top-level scheme is to protect the battery from being damaged and to optimise the overall energy efficiency.

\section{CONCLUSIONS}

Since the hybrid kart consists of different power electronic modules, with different design tasks, the project is well suited for relatively large groups of students. The project is very appealing to the students because the design of an electric vehicle is involved. The ultimate reward is when they can drive the kart around, powered by the models they developed themselves. The students learn to solve complex problems independently, based on a certain design methodology. First, they gather relevant scientific information through a literature survey. Then, they use simulation software to explore the design problems they encounter, and to continuously extend and refine their control models. Finally, the models are verified experimentally on the rapid prototyping hardware platform, and compared with the simulation results obtained earlier.

\section{ACKNOWLEDGMENTS}

The research performed at the K.U.Leuven is financially supported by the Belgian 'Fonds voor Wetenschappelijk Onderzoek (F.W.O.)-Vlaanderen' and the 'Institute for the Promotion of Innovation through Science and Technology in Flanders (IWTVlaanderen)'. Peter Tant is a doctoral research assistant of F.W.O.-Vlaanderen, Jan Verveckken is a doctoral research assistant of IWT-Vlaanderen. The authors express their gratitude to Emrol, for kindly funding the battery packs.

\section{REFERENCES}

[1] Nobels T., et al., "Design of a small personal electric vehicle as an educational project", 11th International Power Electronics and Motion Control Conference, Sept. 2-4, 2004; 5 p.

[2] Lequeu T., Bidoggia B., Derrien Y., Godefroy N., "Two Examples of Pedagogical Applications of Electrical GoKarts", 12th European Conf. on Power Electronics and Applications, Sept. 2-5, 2007; 9 p.

[3] Van Mierlo J., Timmermans J.M., Lataire P., Van den Bossche P., "Project oriented education: Build your own electric go-kart", 11th European Conf. on Power Electronics and Applications, Sept. 11-14, 2005, 9 p.

[4] Triphase, http://www.triphase.com

[5] De Breucker S., et al., "A Hybrid Electric Kart with Energy Flow Management as a Student Project", 19th Int. Symp. on Power Electronics, Electrical Drives, Automation and Motion, June 11-13, 2008; 8 p.

[6] PLECS, http://www.plexim.com/ 